\title{
Permeability Evolution of Shale during Spontaneous Imbibition
}

\author{
Chakraborty, N. ${ }^{1}$, Karpyn, Z.T. ${ }^{1}$, Liu, S. ${ }^{1}$, and Yoon, H. ${ }^{2}$
}

${ }^{1}$ John and Willie Leone Family Department of Energy and Mineral Engineering and EMS Energy Institute, The Pennsylvania State University, University Park, Pennsylvania, USA

${ }^{2}$ Geoscience Research and Applications, Sandia National Laboratories, Albuquerque, NM, USA

\section{Abstract}

Shales have small pore and throat sizes ranging from nano to micron scales, low porosity and limited permeability. The poor permeability and complex pore connectivity of shales pose technical challenges to (a) understanding flow and transport mechanisms in such systems and, (b) in predicting permeability changes under dynamic saturation conditions. This study presents quantitative experimental evidence of the migration of water through a generic shale core plug using micro CT imaging. In addition, in-situ measurements of gas permeability were performed during counter-current spontaneous imbibition of water in nano-darcy permeability Marcellus and Haynesville core plugs. It was seen that water blocks severely reduced the effective permeability of the core plugs, leading to losses of up to $99.5 \%$ of the initial permeability in experiments lasting 30 days. There was also evidence of clay swelling which further hindered gas flow. When results from this study were compared with similar counter-current gas permeability experiments reported in the literature, the initial (base) permeability of the rock was found to be a key factor in determining the time evolution of effective gas permeability during spontaneous imbibition. With time, a recovery of effective permeability was seen in the higher permeability rocks, while becoming progressively detrimental and irreversible in tighter rocks. These results suggest that matrix permeability of ultra-tight rocks is susceptible to water damage following hydraulic fracturing stimulation and, while shut-in/soaking time helps clearing-up fractures from resident fluid, its effect on the adjacent matrix permeability could be detrimental.

\section{Introduction}

The fusion of horizontal well and hydraulic fracture technology in the early 2000s was crucial to unlocking the vast oil and gas resource that shales are. Shales now contribute over $40 \%$ of the total US natural gas production and its share is expected to rise to 55\% by 2040 (EIA, 2016). But despite this massive production boom, the interpretation and management of shales as productive hydrocarbon deposits is still relatively new. In the past, petrophysical assessment of shales was done to evaluate their efficacy as reservoir caps and seals (Katsube et al. 1991) or to address wellbore integrity issues (Horsrud et al. 1998). Today, we possess the tools to produce from these formations but still have scant understanding of the fundamental physics of flow in ultra-tight and nano-porous materials. As a consequence, about one in three shale gas wells have poor production characteristics (Kovscek and Majumdar, 2015). A big opportunity, therefore, exists to 
adapt and improve current reservoir characterization and interpretation in terms of storage and deliverability of shale formations.

Recent studies have focused on characterizing shales at the pore scale and they suggest a complex quad-media porous structure with different porosity, permeability, and wettability domains (e.g., Civan et al. 2012). Experimental work can build on this knowledge to help understand the interactions between these different structural domains, in order to build an appropriate effective medium description of shale. In addition, multiphase flow in shales is an important area of study to understand fluid migration, and shed light on the fate of unrecovered fracturing fluids from stimulation operations and their effect on productivity (Lan et al. 2014, Ghanbari and Dehganpour 2015). Spontaneous fracturing fluid (mostly water) uptake by shales can be attributed to capillary forces, adsorption, or osmosis (Zhou et al. 2016, Ghanbari and Dehganpour 2015). This may cause time-dependent reduction of gas permeability (Bahrami et al. 2011, Pagels et al. 2013), or improve permeability by fracturing caused by clay swelling (Morsy and Sheng 2014).

Simulation tests of fracture-face damage due to fluid invasion, by Holditch 1979, concluded that only when the fracture-face permeability reduction is greater than $99 \%$, will there be any significant productivity impairment in conventional gas wells. Cho et al. 2013 set this threshold at 95\% for shale wells. Both Holditch 1979 and Li et al. 2012 are of the opinion that this level of permeability loss is unlikely to be caused by fracture fluid and leak off. Numerous experimental studies have shown that the permeability in tight rocks can fall by $50 \%$ to $90 \%$ due to the introduction of water blocks (Odumabo et al. 2014, Bostrom et al. 2014, Yan et al. 2015). Some studies on tight sandstones indicate that the lost permeability can recover over time, after injection is ceased (Odumabo et al. 2014, Bostrom et al. 2014). This is mainly due to the redistribution of fluids via spontaneous imbibition that results in a reduction of water saturation within the invaded zone. However, a recent experimental study by Yan et al. 2015 found little-tono permeability improvement in the case of shale.

To our knowledge, there is no work in the literature correlating the evolution of saturation fronts during spontaneous imbibition in shales and their impact on effective permeability to gas. Microcomputed tomography (CT) technology can be used to monitor fluid migration in shales, dynamically and non-destructively. Therefore, this paper presents an experimental study of spontaneous water imbibition in ultra-tight shales, as well as time-dependent gas permeability measurements to assist in filling this knowledge gap. Results from this work are also compared against other in-situ measurements of time-dependent permeability during imbibition (Yan et al. 2015 and Odumabo et al. 2014) to investigate permeability evolution relative to the initial, absolute permeability of the rock, also called "base" permeability.

\section{Methodology}

\subsection{Sample preparation and mineral composition characterization}

Samples of three different shales were extracted from slabbed well cores of $2.75 \mathrm{~cm}$ radius. Smaller plugs were cored for gas permeability measurements $(2.5 \mathrm{~cm}$ in diameter and ranging $1.75-6.25 \mathrm{~cm}$ in length) and for monitoring of saturation profiles during imbibition $(1.27 \mathrm{~cm}$ in 
diameter and $2.8 \mathrm{~cm}$ in length). All samples were heated in an oven for 24 hours at $60^{\circ} \mathrm{C}$ in order to dry out any water that might have been introduced during the coring process. The physical properties and dimensions of the tested shale samples are given in Table 1. While we have attempted to measure matrix permeability without inducing artifacts such as cracks, it was difficult to completely prevent induced fracturing during sample preparation. However, no fractures larger than 9 microns (CT voxel resolution) were observed, with the exception of samples G1 and M2.

Table 1: Physical properties and dimensions of tested shale samples

\begin{tabular}{|c|c|c|c|c|c|c|}
\hline Rock Type & Porosity* & Sample & $\begin{array}{c}\text { Flow vs } \\
\text { Lamination }\end{array}$ & $\begin{array}{l}\text { Diameter } \\
(\mathrm{cm})\end{array}$ & Length $(\mathrm{cm})$ & $\begin{array}{l}\text { Base Permeability } \\
\text { (nd) }\end{array}$ \\
\hline \multirow{4}{*}{ Marcellus } & \multirow{4}{*}{$1.50 \%$} & M1 & Parallel & \multirow{5}{*}{2.54 (1") } & $6.25\left(2.5^{\prime \prime}\right)$ & 58.6 \\
\hline & & $\mathrm{M} 2$ & Parallel & & $4.75\left(1.9^{\prime \prime}\right)$ & $19098(19.1 \mu \mathrm{D})$ \\
\hline & & M3 & Perpendicular & & $1.75\left(0.7^{\prime \prime}\right)$ & Too Low to Measure \\
\hline & & M4 & Perpendicular & & $0.20\left(0.08^{\prime \prime}\right)$ & $\leq 50$ \\
\hline Haynesville & $3.20 \%$ & $\mathrm{H} 1$ & Parallel & & $4.50\left(1.8^{\prime \prime}\right)$ & 173 \\
\hline Generic & N/A & G1 & Parallel & 1.27 (0.5") & 2.8 (1.1") & N/A \\
\hline
\end{tabular}

*Average porosity of multiple rock fragments using Mercury Intrusion Porosimetry

X-ray diffraction (XRD) tests for Haynesville and Marcellus samples are also shown in figure $\mathbf{1 .}$ Samples were crushed and analyzed in a PANalytical Xpert Pro MPD instrument. These revealed Calcite, Quartz, Muscovite, Pyrite and clay minerals - particularly albite - to be the main constituent minerals for both rocks, which suggests limited clay swelling during exposure to water. However, based on experiments and modelling of unconsolidated bead packs with dispersed clays, Aksu et al. 2015 found that both increasing clay content and lowering porosity serves to exacerbate the permeability reduction due to imbibition related swelling. It is reasonable to assume that given their extremely low effective porosity, shales are also susceptible to similar permeability reduction even with modest clay content or minor swelling. 


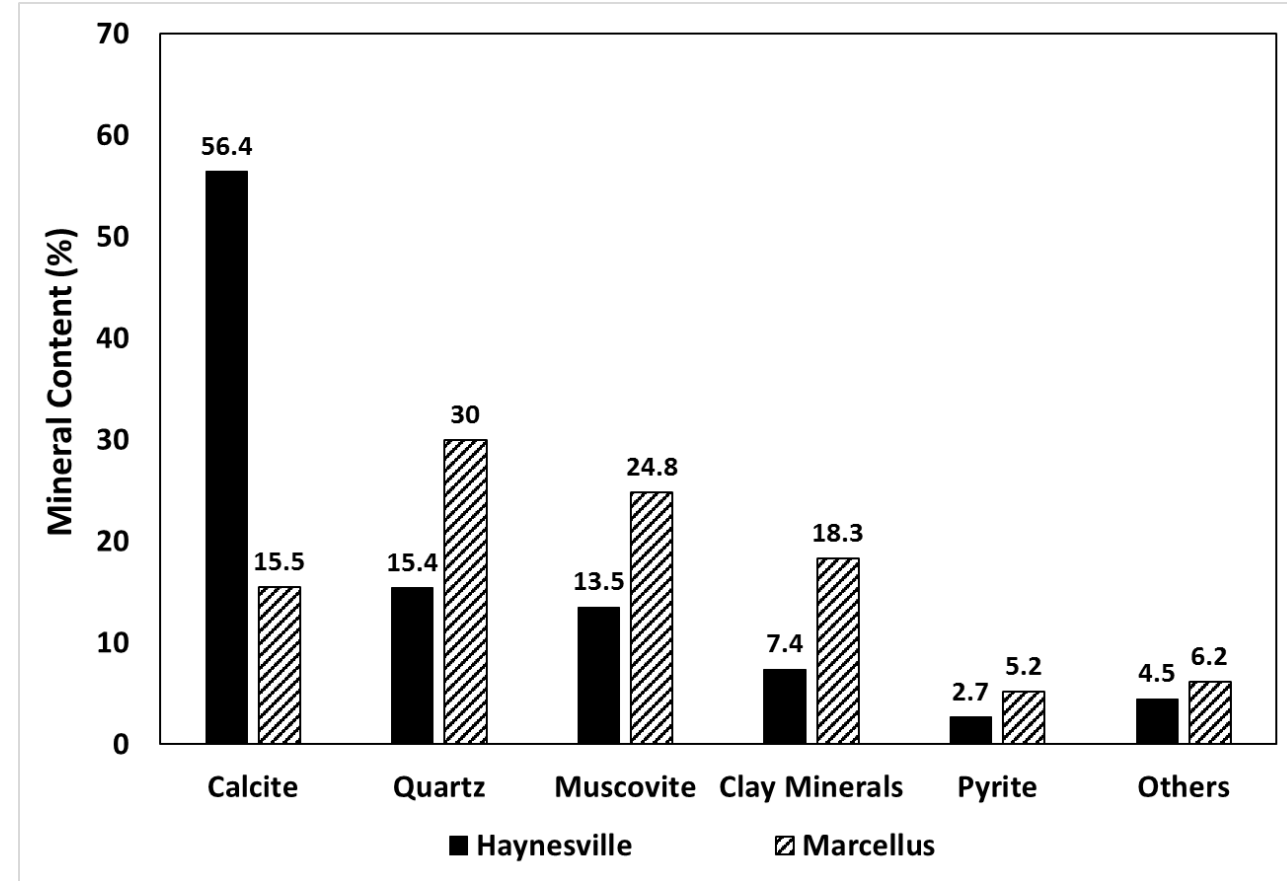

Figure 1: XRD analysis showing mineralogical composition of Haynesville and Marcellus shale samples

\subsection{Experiment 1 - Gravity assisted imbibition}

A gravity assisted imbibition experiment was set up to obtain saturation profiles as a function of time, along the length of the sample. This was done to get a general sense of the time scale of liquid migration in ultra-tight shales. As the first step, the shale sample G1 was jacketed and placed vertically in a glass vial (figure 2). The dry sample was then scanned at a voxel resolution of $9.6 \mu \mathrm{m}$, using X-ray micro CT imaging in a GE Phoenix V Tome-X scanner running at $100 \mathrm{kV}$ voltage and $100 \mu \mathrm{A}$ current. Thereafter, a column of water, with $5 \%$ dissolved $\mathrm{KI}$ as the X-ray contrast enhancer, was placed above the sample and the vial was sealed. X-ray micro CT scanning during imbibition was used to monitor the migration and spreading of the water front at selected time periods: immediately after the introduction of water, after 5 hours, 48 hours and 7 days into the experiment. Each scan lasted 3 hours. 


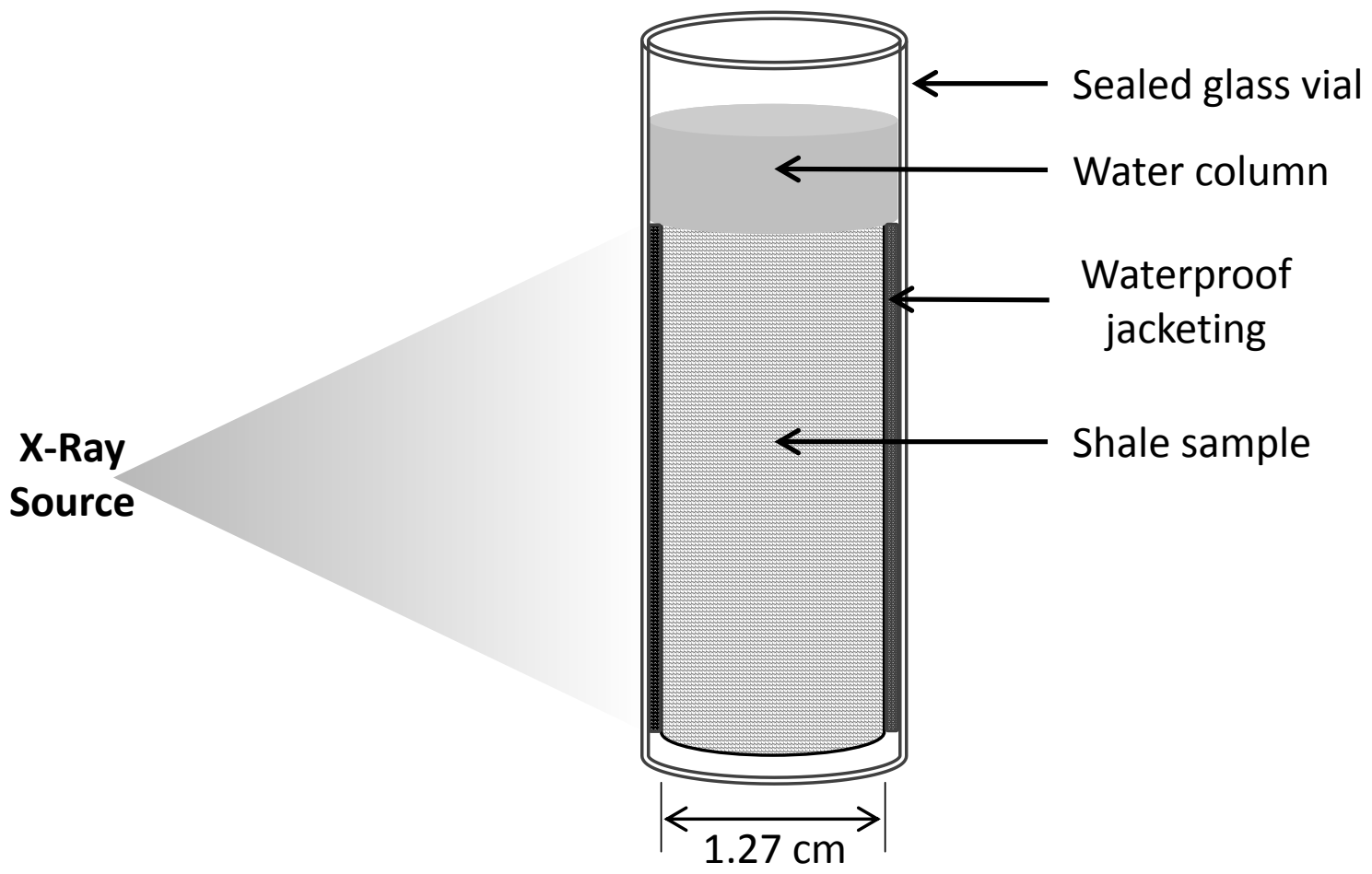

Figure 2: Experimental setup of experiment 1. A column of water is allowed to slowly seep into the shale core due to the effect of gravity and capillary forces

\subsection{Experiment 2 - Permeability evolution during spontaneous imbibition}

Experiment 2 consisted of initiating a spontaneous imbibition front in selected core samples while countercurrent gas permeability measurements were performed as a function of time. Figure 3 illustrates the experimental procedure in three sequential steps. 


\section{Step 1: \\ Base perm.}

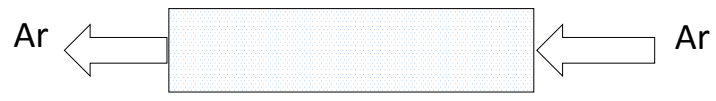

\section{Step 2: \\ Leak off}

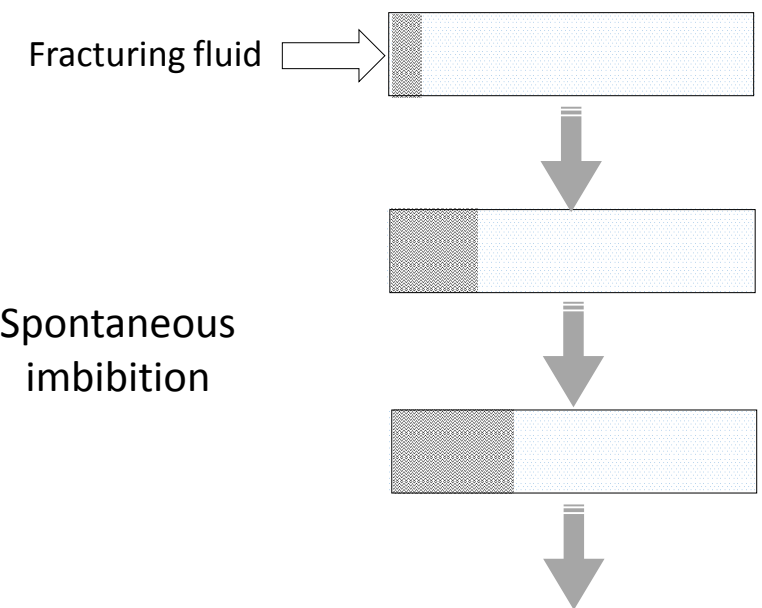

\section{Step 3:}

Flow back

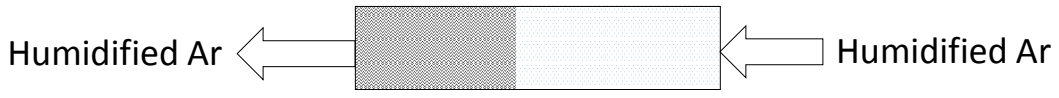

Figure 3: Experimental procedure for experiment 2 - permeability evolution during spontaneous imbibition [Note: 16.55MPa confining pressure was kept constant]

The first step of the process was to measure the permeability of the dry core plug in order to obtain a base permeability using Argon gas. Next, 5\% KI solution was injected at $\sim 13.8 \mathrm{MPa}$ (2000psi) for several hours in order to establish a zone of high water saturation near the downstream face of the sample. These conditions allowed for a comparable depth of penetration of the KI solution to those reported in previous experiments using tight sands and shale cores, which were used for comparison purposes. The water injection time was approximately $18 \mathrm{hr}$, 2.5min, and 4.5hr for samples M1, M2 and H1, respectively. Injection was then stopped and there were no further pressure gradients applied across the samples to force liquid flow. This allowed for all subsequent imbibition and redistribution of water to be spontaneous. Counter current gas permeability measurements were taken periodically at intervals of $\sim 24$ hours.

Attempts to accurately measure the introduced water saturation, both volumetrically and via imaging, failed because of the ultra-low porosity of the samples and poor X-ray signal-to-noise ratio within the pressure vessel. Therefore, these are not reported in this paper. Alternate imaging without the pressure vessel are presented separately.

To measure effective gas permeability on the order of a few tens of nano-Darcies in reasonable time frames, a pulse-decay approach was adopted. For this purpose, a modified version of Jones 1997 was custom built (figure 4). The pulse-decay permeability measurement is based upon the basic principle that when a gas pressure differential is applied across the two ends of a core plug sample, the rate of gas diffusion through the rock plug reflects in the rate at which the upstream and downstream pressures equilibrate, and this data can be used to compute the permeability of the sample. A key parameter controlling the speed of measurements is the ratio of the upstream 
and downstream pressure application volumes $\left(\mathrm{V}_{1}\right.$ and $\left.\mathrm{V}_{2}\right)$ to the pore volume $\left(\mathrm{V}_{\mathrm{p}}\right)$. The fastest accurate measurements occur when these ratios are close to unity. Since shales have very low porosity, $\mathrm{V}_{\mathrm{p}}$ was often just a few milliliters for a $2.5 \mathrm{~cm}$ cylindrical core. Therefore, $\mathrm{V}_{1}$ and $\mathrm{V}_{2}$ had to be very small and were just the volumes of the flowlines between the upstream and downstream valves. A second parameter that contributes to faster and more accurate pulse-decay measurements is high mean gas flowing pressure (Jones 1997). Thus, a mean gas pressure of $6.9 \mathrm{MPa}$ (1000psia) was chosen, which was applied at the beginning of every permeability test using volumes $V_{3}$ and $V_{4}$, until static equilibrium was attained. This mean pressure was maintained during gas flow as well by setting up the pressure pulse with upstream pressure at $7.6 \mathrm{MPa}$ (1100psia) and downstream pressure of 6.2MPa (900psia). While it is possible that this gas pressure pulse may have affected the distribution of resident water, no fluid backflow was observed during testing.

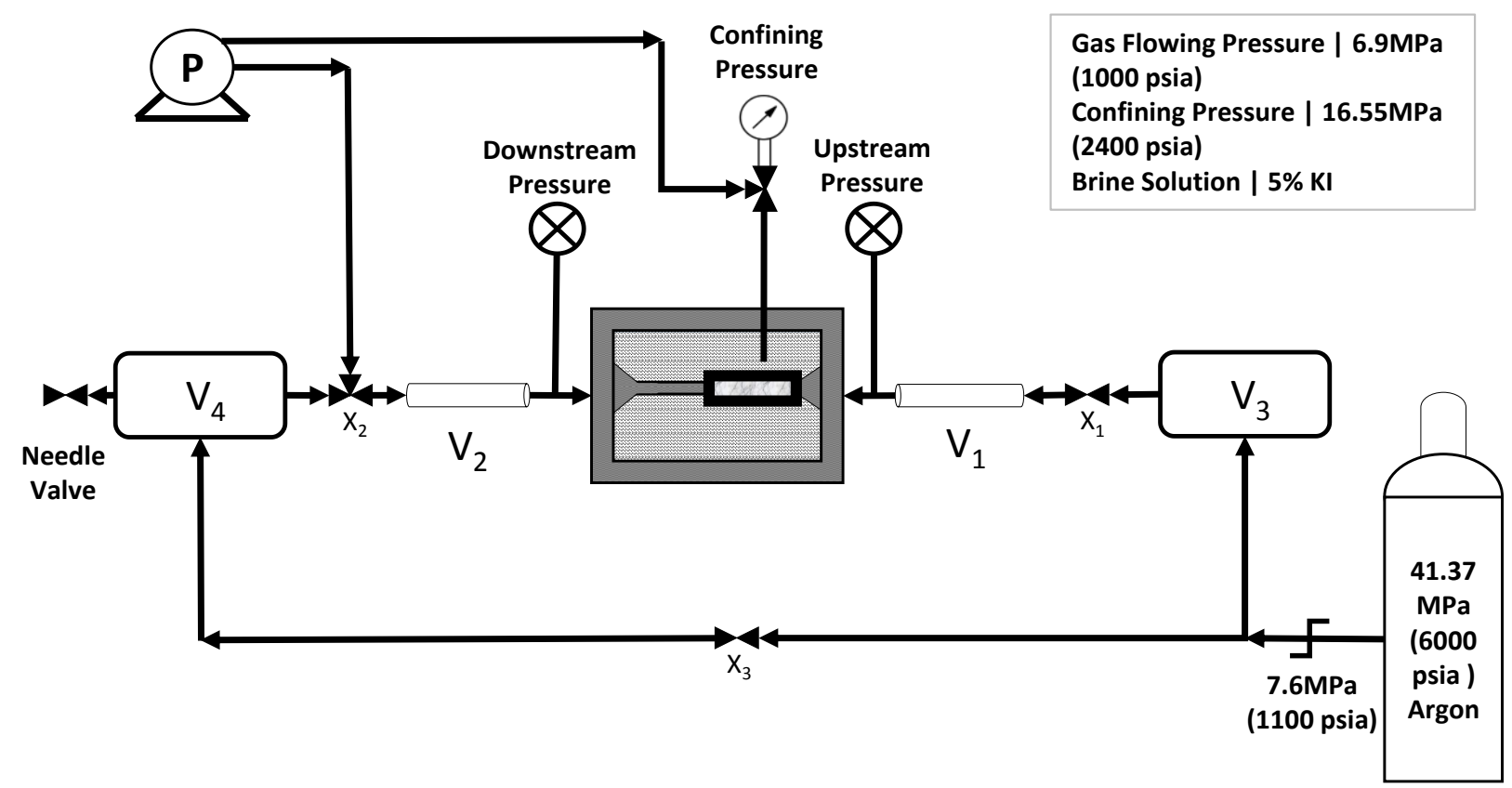

Figure 4: Schematic of Pulse Decay Permeameter

The shale samples were jacketed using polyolefin heat shrinkage tubing and a hydraulic confining pressure was applied around the sealing jacket in the pressure vessel. A major challenge in this experiment was that the low permeability of the shales made them vulnerable to gas bypass between the sides of the core plug and the sealing jacket, which could result in gross overestimations of permeability. In order to minimize this gas bypass, the confining pressure was set at $16.5 \mathrm{MPa}(2400 \mathrm{psia})$, which is twice the maximum gas pressure (7.6MPa in the upstream). This core holder assembly formed the heart of the pulse-decay permeability setup.

The time frame of pulse decay measurements is highly sensitive to the average permeability of the samples. The time taken for pressure pulse equilibration was typically less than 2 hours for permeability measurements of higher than 100nd, and longer than 72 hours for permeabilities less than 10nd. For measurements that would have otherwise taken several days, permeability calculation was done based on the initial 24-hour straight-line slope of the pressure decay versus time semi-log graph (figure 5). 
Figure 5: Sample result from a pulse decay experiment that yielded a permeability of $14.4 \mathrm{nd}$. To shorten the time taken to get a permeability reading, the experiment was truncated at a pressure difference of 15 psia. This was not a problem because a clear straight line decline region was readily identifiable

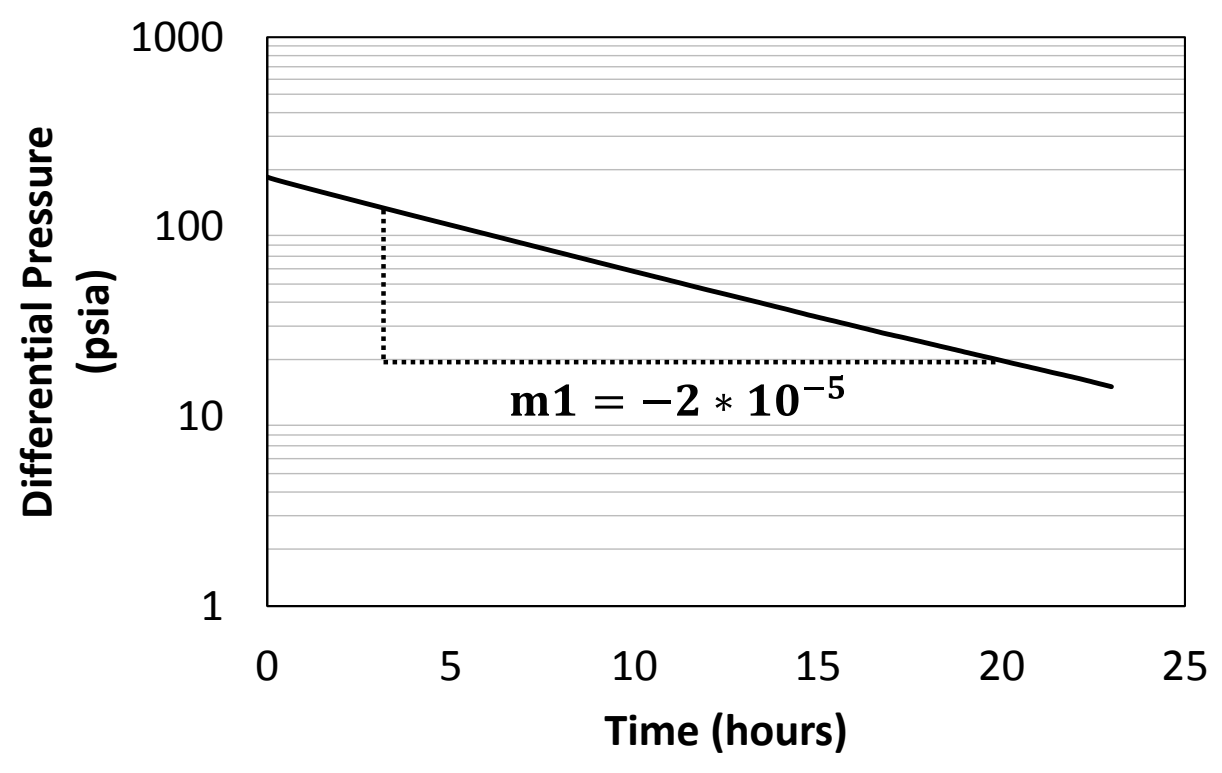

\section{Results and Discussion}

\subsection{Experiment 1 - Observations on gravity assisted imbibition}

Figure 6 shows micro CT images of the G1 sample at various stages of experiment 1 . As indicated in figure 6 (b), after the first scan $(0-3 \mathrm{hr})$, the injected water is seen to be concentrated in the micro-fractures F1 and F2 of sample G1. The plane of these fractures cuts across the sample diameter indicating that the fractures are coring induced. They also have relatively large 
apertures ranging from $1-30 \mu \mathrm{m}$. Over the next 7 days, water spreads outward from these two fractures and into the matrix due to spontaneous imbibition. The evidence for spontaneous imbibition is the disappearance of water from the fractures as seen in images (b) and (c) of figure 6. Since this is gravity assisted flow, the disappearance of water from the fractures indicates that the high permeability channels, which initially allowed the flow of water to the fractures, have closed off. This closure may be related to clay swelling. Evidence of swelling is also seen from the fact that fractures F1 and F2 almost disappear over the course of the experiment. This is surprising because the 5\% KI solution should have acted to stabilize clays, and, there were no other obvious signs of swelling when the sample was taken out of the experimental setup. This observation warrants more research on ascertaining the extent to which different types of stabilizers added in the field can prevent swelling over long periods of time.

Figure 7 shows the profiles of water saturation along the sample length, extracted from the micro CT data. The first profile (0-3hr) indicates a rapid initial buildup of water in-and-around the fractures F1 and F2. This is likely due to the presence of a nearly vertical fracture connecting the injection face of the sample to the F1 fracture. However, it was below the limit of resolution of the scan and therefore a clear visual confirmation of this vertical fracture could not be made. The closure of this fracture would explain why the fluid supply to fractures F1 and F2 seems to get cut-off after 3 hours. Thus, without sufficient continued supply, the majority of the fluid in F1 and F2 disappear into the matrix over 48 hours. The transport of water through the matrix is a slower process which becomes more important by day 7 . That is why we see higher saturation near the inlet end of sample, systematically reducing through the sample's length. 

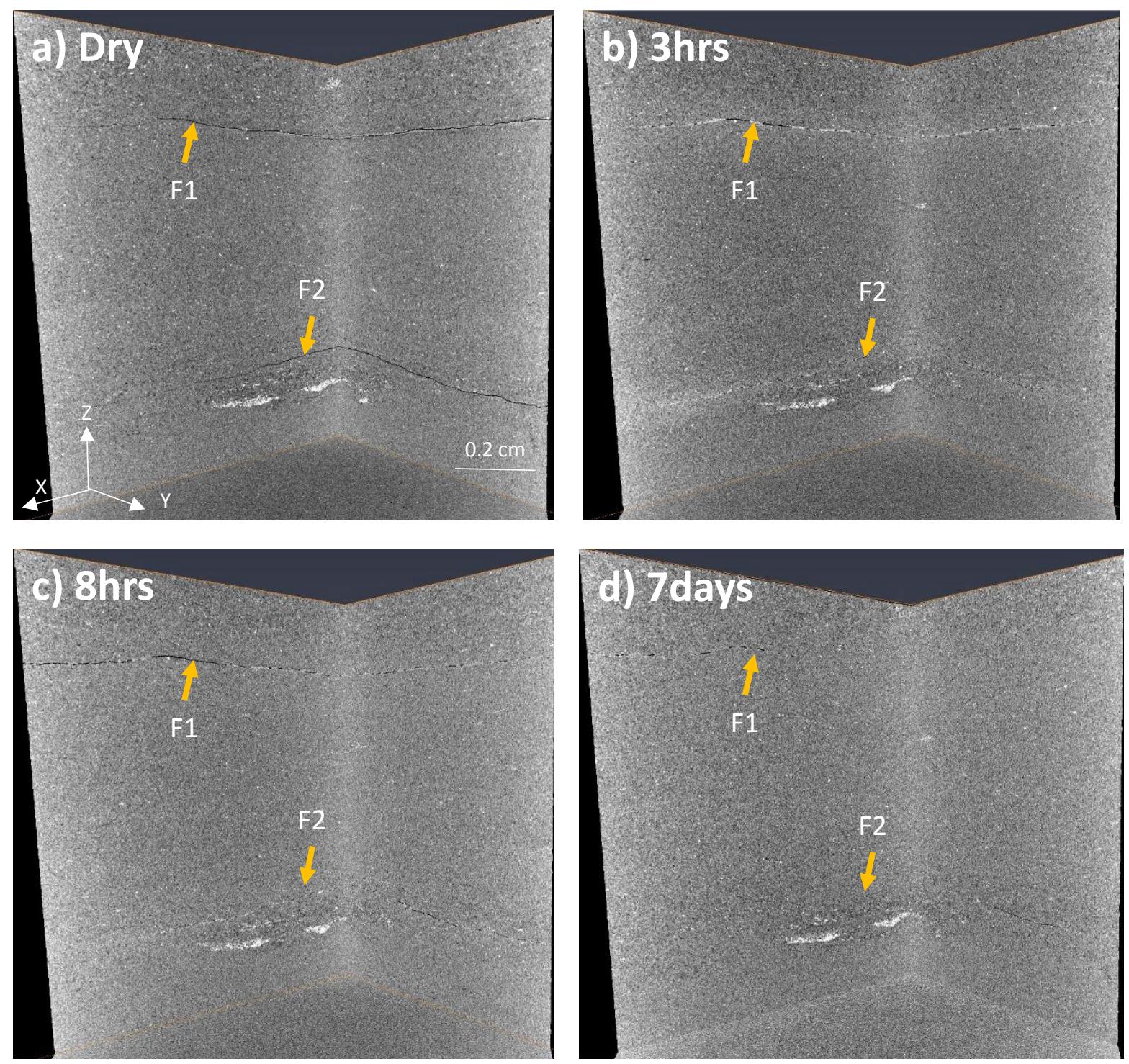

Figure 6: Magnified X-ray images of a 3D sector near the injection end of sample G1. Water is introduced from top. a) Initial scan of sample prior to introduction of water, b) 0-3 hour scan showing fractures F1 and F2 to be filled with water (tagged white), c) 5-8 hour scan showing signs of disappearance of water from the fractures despite the continued presence of the overhead water column, d) Scan 7 days into the experiment indicating the closure of fractures F1 and F2 


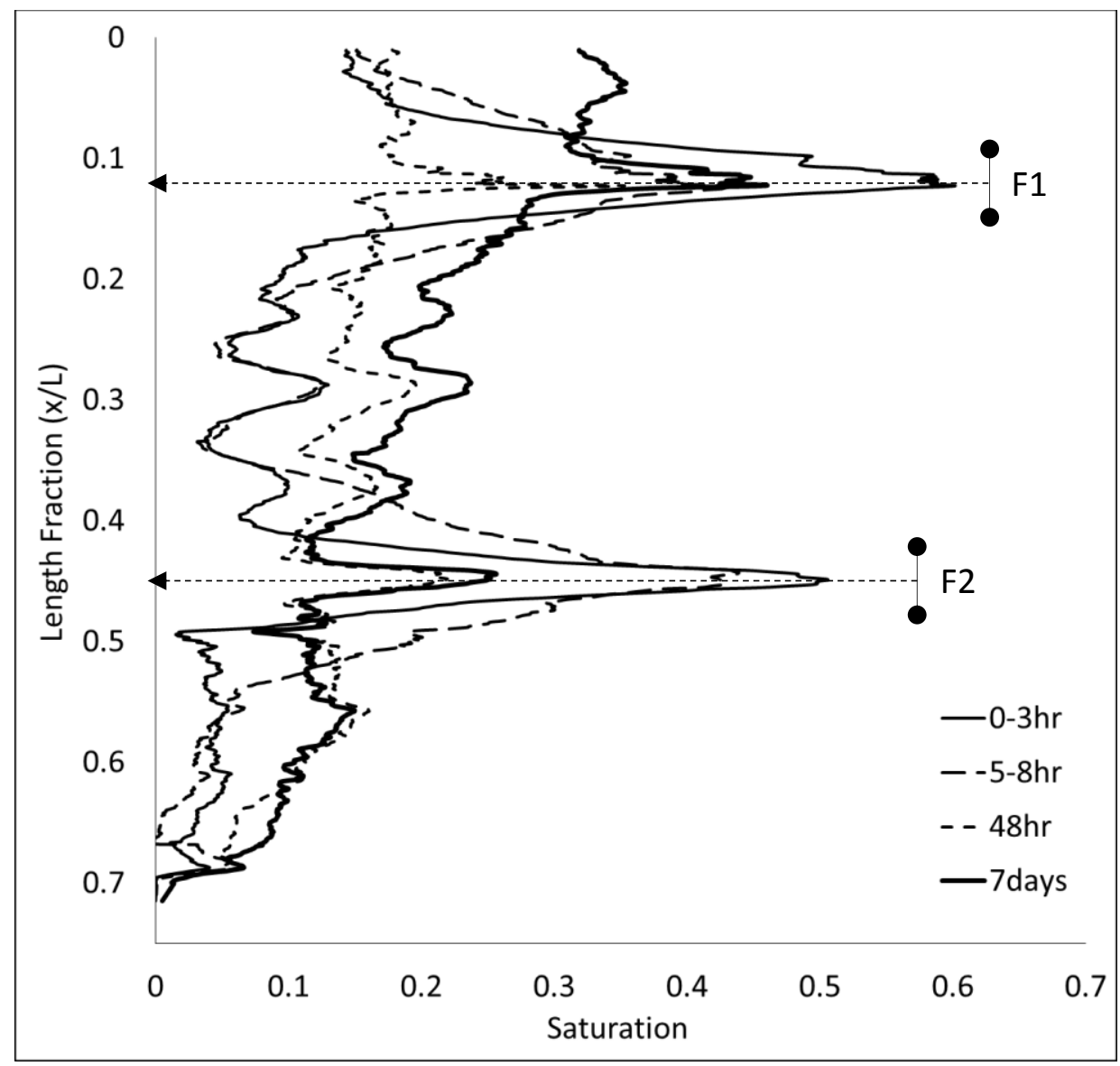

Figure 7: Saturation profile indicating presence of water along the length of the core sample obtained from image subtraction of the CT data. Each data point indicates the average saturation of a planar cross-sectional region of the core [Note: Saturations assume an uniform average porosity of 5\%]

\subsection{Experiment 2 - Observations on permeability evolution during spontaneous imbibition}

The first step in the permeability evolution experiments consisted of measuring base permeability to gas, and are reported in Table 1. Most of the base permeabilities measured are "ultra-low", with values under 200nd. Sample M2 was the only outlier, with an exceptionally high reading of $19.1 \mu \mathrm{d}$. This was due to a transverse fracture running along the length of the core plug.

The results in Table 1 indicate significant differences between measured permeabilities for Marcellus samples cored parallel vs perpendicular to lamination. Samples M3 and M4 were cored perpendicular to lamination and show much lower permeability than other shale samples. The measured value for M3 was below the lower limit of precision for the pulse decay apparatus ( $<<1$ nd). Permeability of sample M4 was measured via steady-state flow experiments, with the intention to validate the pulse decay procedure. While this yielded 50nd, it must be pointed out that the flow rate increased sharply towards the end of the experiment, suggesting that the applied injection pressure had fractured the rock. Therefore, the original base permeability of M4 could be less than the reported 50nd. 
Figure 8 shows the evolution of effective permeability to gas through the spontaneous imbibition experiments. It contains results of experiments on rocks having absolute permeability between 58.6nd to $4.8 \mathrm{md}$. The first data point on each curve is the absolute permeability while the second data point represents permeability immediately after the introduction of water. In all cases, permeability was found to drop due to the introduction of water, with the drop being most significant among ultra-tight samples M1, M2 and H1. Samples M1 and H1 lost 93\% and 88\% of their base permeability respectively, while the fractured M2 sample was affected even more, losing $99 \%$ of its permeability. Most likely, this is because of the choking of its main flow artery - the transverse fracture - leading to a permeability drop closer to "true" matrix permeability levels of M2. Figure 8 also shows results from similar experiments done by Odumabo et al. 2014 on tight sands and Yan et al. 2015 on shales. Permeability loss was reported at 40-50\% for tight sands by Odumabo et al. 2014 and 70-80\% for shale samples by Yan et al. 2015. Both sets of experiments were carried out under similar initial conditions.

It is important to mention that there are differences between the samples presented in Figure 8, such as mineralogy, initial saturation state, porosity, permeability etc. There are also subtle differences between experimental methodologies adopted in this study compared to those of Odumabo et al. 2014 and Yan et al. 2015, for example, sample preparation protocols, and specific experimental conditions such as gas moisture content and flowing pressures. Nonetheless, a systematic trend emerges when the results are grouped using base permeability. Samples with base permeability in the nano-darcy range - M1 and H1 - saw significant reduction with time, each losing approximately $99.5 \%$ of base permeability by the end of the experiment. The rate of permeability reduction was also faster for the tighter Marcellus M1 sample. However, for samples with base permeability in the micro-darcy range, permeability did not change significantly over time, as observed by Yan et al. 2015. Sample M2 saw a significant drop in permeability upon the introduction of water, dropping from 19 to $0.22 \mu \mathrm{d}$. However, it showed a rapid recovery to $10 \mu \mathrm{d}$ as its main flow channel cleared up, and subsequently, followed a similar trend as observed in other micro-darcy samples. The permeability declined marginally to $6 \mu \mathrm{d}$ at the end of the experiment. Finally, among the milli-darcy permeability tight sand samples studied by Odumabo et al. 2014, permeability recovery of up to $30 \%$ of base permeability was observed.

These results suggest that base permeability is a determining factor in predicting the temporal permeability response, with higher permeability samples showing improvements, while tighter samples show little benefit or even see reductions in permeability with time. 


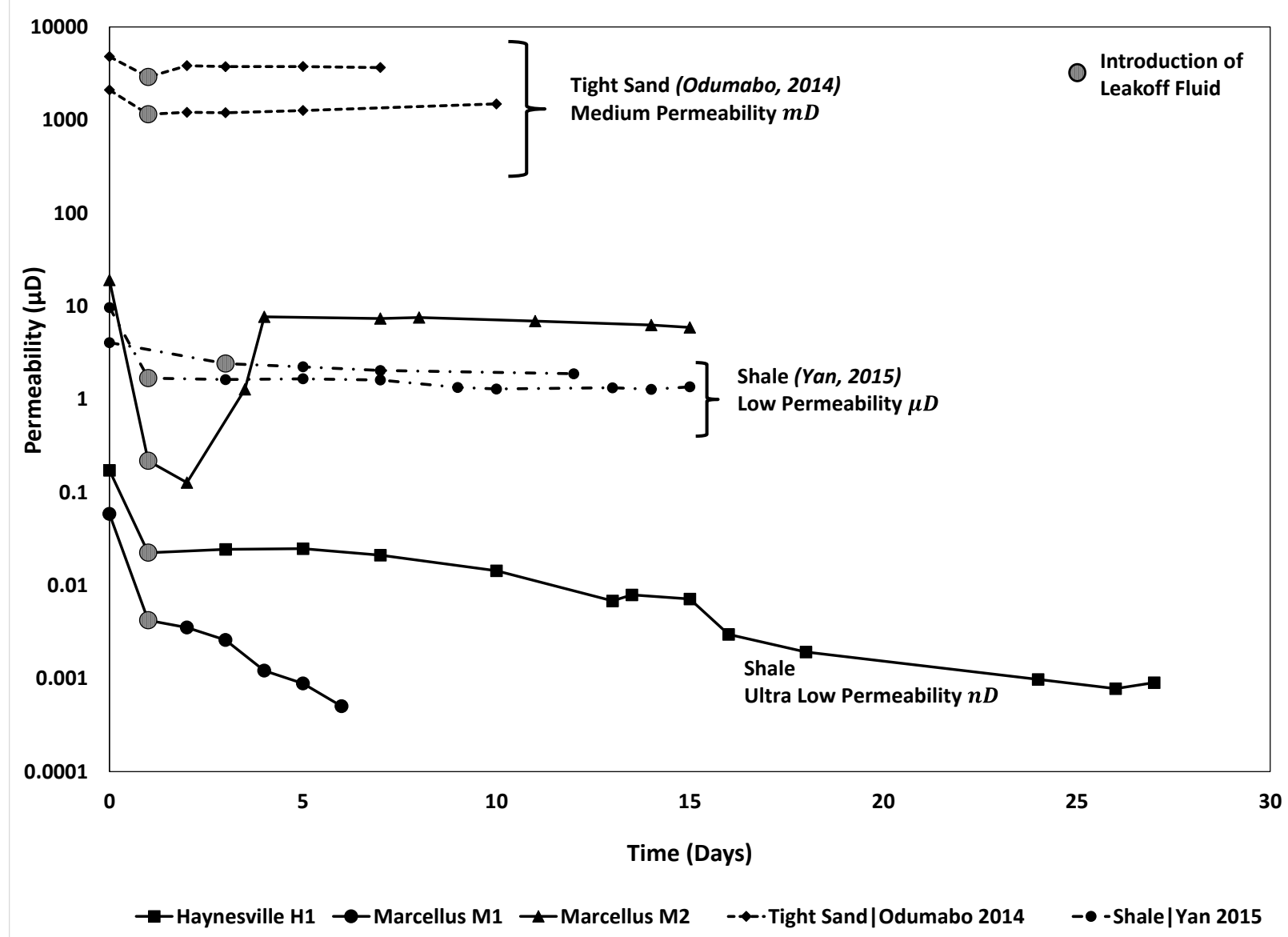

Figure 8: Comparing tight sands, fractured shales and ultra-tight shales. Permeability evolution with soaking time is a function of base permeability

One or more of the following reasons may be used to explain the above observations:

1. Systems with micro-darcy permeability $(k>1 \mu \mathrm{d})$

Fractured shales have permeability in the micro-darcy range with their main flow channels being the fractures. Their relatively large apertures reduce the impact of fracture closure due to swelling. Thus, when these fractures are saturated with liquid, gas permeability drops several orders of magnitude to true matrix levels. Since capillary imbibition of liquid is a function of mean size of flow channels, strong capillary forces exist in the neighboring matrix. These forces draw out this liquid from the fracture and into the matrix fairly quickly, leading to a significant permeability recovery.

A similar process leads to permeability recovery in sandstones, with the difference being that the liquid block initially exists, and is subsequently distributed, within the matrix owing to spontaneous capillary imbibition.

2. Systems with nano-darcy permeability $(k<300$ nd $)$

In ultra-tight nano-darcy systems, the flow channels - porosity or fracture - are much smaller. This magnifies the scale of gas permeability reduction caused by the presence of liquids. The surface area of these nano flow channels is high, thus exacerbating effects such as clay swelling 
and particle agglomeration. Capillary forces are insufficient to overcome the inherently low permeability of these systems, and redistribution of fluid from liquid blocks is not as effective. This might explain the decline in permeability with time observed in this study and the irreversible damage to absolute permeability observed at the lab scale by Yan et al. 2015.

\section{Conclusions}

In this work, we have investigated the time-evolution of effective permeability to gas in ultratight shale cores in the presence of an imbibing water front. Pre-existing and induced fractures play a dominant role in the initial uptake of water, while matrix imbibition operates over a longer time frame. The shale samples tested exhibit significant permeability anisotropy with permeability measured parallel to lamination in the range of tens of micro-darcy ( $\mu \mathrm{d})$ for fractured samples, nano-darcy (nd) for intact samples, and nearly unmeasurable permeability in samples cored perpendicular to lamination.

Effective gas permeability measurements in ultra-tight shales showed an initial permeability reduction of $90 \%$ to $99 \%$ from its original state upon water injection. With time, permeability dropped even further by up-to two orders of magnitude due to spontaneous imbibition of water deeper into the sample and swelling-related hindrance. In contrast, experiments by other researchers on tight sands and higher permeability shales found lesser impairment of initial permeability and subsequent recovery with time. These results demonstrate that permeability evolution is strongly determined by base permeability, which suggests important parallelisms with the impact of water-based hydraulic fracturing fluids during stimulation of ultra-tight shale reservoirs, where matrix permeability appears to be more susceptible to water damage in shales than in conventional rocks. And, while soaking (shut-in) time may help to clear up the fluid residing in the fractures via matrix imbibition, its long-term effect on the effective permeability to gas could be detrimental.

\section{Acknowledgements}

This work received funding support from the U.S. Department of Energy, the Office of Science, Basic Energy Sciences program under Award Number DE-SC0006883. Sandia National Laboratories is a multi-program laboratory managed and operated by Sandia Corporation, a wholly owned subsidiary of Lockheed Martin Corporation, for the U.S. Department of Energy's National Nuclear Security Administration under contract DE-AC04 94AL85000. We also thank Tim Beattie from Shell Appalachia, and the Unconventional Natural Resources Consortium (UNRC), for facilitating Marcellus shale samples for this study. 


\section{References}

Aksu, I., E. Bazilevskaya, and Z. T. Karpyn. "Swelling of Clay Minerals in Unconsolidated Porous Media and Its Impact on Permeability." GeoResJ 7 (September 2015): 1-13. doi:10.1016/j.grj.2015.02.003.

Bahrami, Hassan, Mohammad Reza Rezaee, Delair Honer Nazhat, Jakov Ostojic, Michael Benedict Clennell, and Ahmad Jamili. "Effect of Water Blocking Damage on Flow Efficiency and Productivity in Tight Gas Reservoirs." Society of Petroleum Engineers, 2011. doi:10.2118/142283-MS.

Bostrom, N., M. Chertov, M. Pagels, D. Willberg, A. Chertova, M. Davis, and W. Zagorski. "The Time-Dependent Permeability Damage Caused by Fracture Fluid." In SPE-168140MS. SPE: Society of Petroleum Engineers, 2014. doi:10.2118/168140-MS.

Cho, Younki, Erdal Ozkan, and Osman G. Apaydin. "Pressure-Dependent Natural-Fracture Permeability in Shale and Its Effect on Shale-Gas Well Production." SPE Reservoir Evaluation \& Engineering 16, no. 02 (May 1, 2013): 216-28. doi:10.2118/159801-PA.

Civan, Faruk, Deepak Devegowda, and Richard Sigal. "Theoretical Fundamentals, Critical Issues, and Adequate Formulation of Effective Shale Gas and Condensate Reservoir Simulation." In Porous Media and Its Applications in Science, Engineering, and Industry, edited by K. Vafai, 1453:155-60. Melville: Amer Inst Physics, 2012.

Energy Information Administration. 2016. International Energy Outlook 2016, http://www.eia.gov/forecasts/ieo/pdf/0484(2016).pdf (downloaded 7 September 2016).

Ghanbari, Ebrahim, and Hassan Dehghanpour. "The Fate of Fracturing Water: A Field and Simulation Study." Fuel 163 (January 1, 2016): 282-94. doi:10.1016/j.fuel.2015.09.040.

Holditch, Stephen A. "Factors Affecting Water Blocking and Gas Flow From Hydraulically Fractured Gas Wells." Journal of Petroleum Technology 31, no. 12 (December 1, 1979): 1515-24. doi:10.2118/7561-PA.

Horsrud, P., E. F. SØnstebØ, and R. BØe. "Mechanical and Petrophysical Properties of North Sea Shales." International Journal of Rock Mechanics and Mining Sciences 35, no. 8 (December 1998): 1009-20. doi:10.1016/S0148-9062(98)00162-4.

Katsube, T. J., Brett S. Mudford, and M. E. Best. "Petrophysical Characteristics of Shales from the Scotian Shelf." Geophysics 56, no. 10 (October 1, 1991): 1681-89. doi:10.1190/1.1442980.

Kovscek, Anthony R., and Arun Majumdar. Natural Gas Resources, Natural Gas Utilization and Potential Climate/Pollution Benefits. Vol. 1. 3 vols. Energy Seminar, Natural Gas MiniSeries. Stanford: NVIDIA Auditorium, Jen-Hsun Huang Engineering Center, 2015. http://energyseminar.stanford.edu/node/637.

Lan, Qing, Ebrahim Ghanbari, Hassan Dehghanpour, and Robert Hawkes. "Water Loss Versus Soaking Time: Spontaneous Imbibition in Tight Rocks." Energy Technology 2, no. 12 (December 1, 2014): 1033-39. doi:10.1002/ente.201402039.

Li, Jun, Boyun Guo, Deli Gao, and Chi Ai. "The Effect of Fracture-Face Matrix Damage on Productivity of Fractures With Infinite and Finite Conductivities in Shale-Gas Reservoirs." SPE Drilling \& Completion 27, no. 03 (September 1, 2012): 348-54. doi:10.2118/143304PA. 
Morsy, Samiha, and J.J. Sheng. "Imbibition Characteristics of the Barnett Shale Formation." Society of Petroleum Engineers, 2014. doi:10.2118/168984-MS.

Odumabo, S.M., Zuleima T. Karpyn, and Luis F. Ayala H. "Investigation of Gas Flow Hindrance due to Fracturing Fluid Leakoff in Low Permeability Sandstones." Journal of Natural Gas Science and Engineering 17 (2014): 1-12. doi:10.1016/j.jngse.2013.12.002.

Pagels, Markus, Dean M. Willberg, Eric Edelman, William Zagorski, and Joe Frantz. "Quantifying Fracturing Fluid Damage on Reservoir Rock to Optimize Production," 176674. Society of Exploration Geophysicists, American Association of Petroleum Geologists, Society of Petroleum Engineers, 2013. doi:10.1190/urtec2013-180.

Yan, Qiyan, Christina Lemanski, Zuleima T. Karpyn, and Luis F. Ayala H. "Experimental Investigation of Shale Gas Production Impairment due to Fracturing Fluid Migration during Shut-in Time." Journal of Natural Gas Science and Engineering 24 (2015). doi:10.1016/j.jngse.2015.03.017.

Zhou, Z., H. Abass, X. Li, D. Bearinger, and W. Frank. "Mechanisms of Imbibition during Hydraulic Fracturing in Shale Formations." Journal of Petroleum Science and Engineering 141 (May 2016): 125-32. doi:10.1016/j.petrol.2016.01.021. 